\title{
АВТОМАТИЗАЦІЯ ПРОЦЕСУ ДІАГНОСТУВАННЯ СПАДКОВИХ МЕТАБОЛІЧНИХ ЗАХВОРЮВАНЬ ІЗ ВИКОРИСТАННЯМ ІНФОРМАЦІЙНО- АНАЛІТИЧНОЇ СИСТЕМИ РАННЬОЇ ДІАГНОСТИКИ
}

\author{
В. 3. Стецюк, О. І. Лісовиченко, А. В. Малєй, \\ О. Д. Фіногенов, Н. В. Ольхович ${ }^{1}$, Н. О. Пічкур ${ }^{1}$ \\ Національний технічний університет України \\ Київський політехнічний інститут імені Ігоря Сікорського» \\ ${ }^{1}$ Національна дитяча спеціалізована лікарня «ОХМАТДИТ»

\footnotetext{
У статті розглядається можливість автоматизованого застосування протоколів раннього діагностування в пацієнтів спадкових метаболічних захворювань. Пропонується покращення алгоритму діагностування захворювань у пацієнтів із погляду на швидкість обчислень. Описано спосіб допомоги лікарю відділення орфанних захворювань НДСЛ «ОХМАТДИТ» при встановленні діагнозу.

Описано інструменти та методи, що використовуються в комплексі програмного забезпечення.
}

Ключові слова: орсанні захворювання, інформатизація, симптом, гіпотеза, модель розпізнавання, інтерфейс користувача, нейромережі, штучна нейромережа.

\section{AUTOMATION OF THE HEREDITARY METABOLIC DISEASES DIAGNOSING PROCESS USING THE INFORMATION AND ANALYTICAL SYSTEM OF EARLY DIAGNOSIS}

\author{
V. Z. Stetsiuk, O. I. Lisovychenko, A. V. Maliei, \\ O. D. Finogenov, N. V. Olhovich ${ }^{1}$, N. O. Pichkur ${ }^{1}$ \\ National Technical University of Ukraine \\ «Igor Sikorsky Kyiv Polytechnic Institute» \\ ${ }^{1}$ National specialized children hospital «OKHMATDYT»
}

\begin{abstract}
The article deals with the possibility of automated application of protocols for early diagnosis in patients with hereditary metabolic diseases. An improvement in diseases diagnosing algorithm with regard to the computing speed is proposed. A method for assisting the doctor of orphan disease department of the NCSH «OKHMADYT» in the process of diagnosing is described.

The article describes tools and methods used in the software package.
\end{abstract}

Key words: orphan diseases, informatization, symptom, hypothesis, recognition model, user interface, neural networks, artificial neural network. 


\title{
АВТОМАТИЗАЦИЯ ПРОЦЕССА ДИАГНОСТИРОВАНИЯ НАСЛЕДСТВЕННЫХ МЕТАБОЛИЧЕСКИХ ЗАБОЛЕВАНИЙ С ИСПОЛЬЗОВАНИЕМ ИНФОРМАЦИОННО-АНАЛИТИЧЕСКОЙ СИСТЕМЫ РАННЕГО ДИАГНОСТИРОВАНИЯ
}

\author{
В. 3. Стецюк, О. И. Лисовиченко, А. В. Малей, \\ А. Д. Финогенов, Н. В. Ольхович ${ }^{1}$, Н. А.Пичкур ${ }^{1}$ \\ Национальный технический университет Украины \\ «Киевский политехнический институт имени Игоря Сикорского» \\ ${ }^{1}$ Национальная детская специализированная больница «ОХМАТДЕТ»
}

\begin{abstract}
В статье рассматривается возможность автоматизированного применения протоколов раннего диагностирования у пациентов наследственных метаболических заболеваний. Предлагается улучшение алгоритма диагностики заболеваний у пациентов с точки зрения скорости вычислений. Описан способ помощи врачу отделения орфанных заболеваний НДСБ «ОХМАТДЕТ» при установлении диагноза.

Описаны инструменты и методы, используемые в комплексе программного обеспечения.
\end{abstract}

Ключевые слова: орфанные заболевания, информатизация, симптом, гипотеза, модель распознавания, интерфрейс, нейросети, искусственная нейросеть.

Вступ. На сьогодні розвиток такої науки, як генетика, значно пришвидшився. Вчені з України та інших країн активно працюють над класифікацією нині існуючих метаболічних захворювань, кількість яких, як виявилося, вираховується сотнями. На жаль, лікувати ці захворювання сучасній медицині дуже складно. Проте своєчасне розпізнавання того чи іншого захворювання допомагає лікарям надавати своєчасну необхідну допомогу новонародженим. Варто зазначити, що історія хвороби пацієнтів центру метаболічних захворювань містить значно більше інформації, ніж історія хвороби пацієнтів інших відділень, оскільки усі, без виключень, зовнішні чи внутрішні особливості пацієнтів вказаного центру мають велике значення [2, 3, 6].

На сучасному етапі розвитку лікарі-генетики змушені витрачати дорогоцінний час не на прийом пацієнтів, а на заповнення вручну історій хвороб пацієнтів, оскільки стандартні медичні програми для такого заповнення не мають відповідної класифікації. Саме для надання можливості лікарям-генетикам звільнитися від рутинної роботи 3 картками і створено даний програмний продукт.

Діагностика спадкових хвороб обміну речовин за виникаючими симптомами представляється досить складним завданням. Це пов’язано з загальними симптомами вказаних захворювань, що “маскуються” під більш поширені хвороби. Зміна активності ферментів обумовлює різні розлади обміну, що веде до появи великої різноманітності симптомів. У деяких випадках ознаки захворювання, що виникають у людини, можуть бути пов'язаними з дуже тяжкою патологією і можуть призвести до летального результату ще в періоді новонародженості, деякі призводять до стійкої розумової відсталості та інвалідності. Іноді порушення обміну супроводжуються менш вираженими симптомами або протікають з повною їх відсутністю [3].

Мета роботи: представлення методів автоматизації процесу діагностування спадкових метаболічних захворювань з використанням інформаційноаналітичної системи ранньої діагностики.

Головна ідея розроблення всього комплексу полягає в поєднанні сучасних методик лікування пацієнтів, що відповідають міжнародним стандартам, та об’ємної історії лікування пацієнтів Центру орфанних захворювань Національної дитячої спеціалізованої лікарні (НДСЛ) «Охматдит». Далеко не в кожного пацієнта, який звертається до вказаного центру, захворювання може легко i просто діагностувати. Адже лікар бачить лише певні симптоми, в різних поєднаннях, і спершу має змогу лише висловити підозру на те чи інше орфанне захворювання. Для подальшого ж діагностування часто необхідно зробити цілу низку аналізів, що, знову ж таки, не завжди однозначно підкажуть діагноз захворювання, а лише вкажуть на показники: що відповідають нормі та/або відхиляються від норми [4]. 


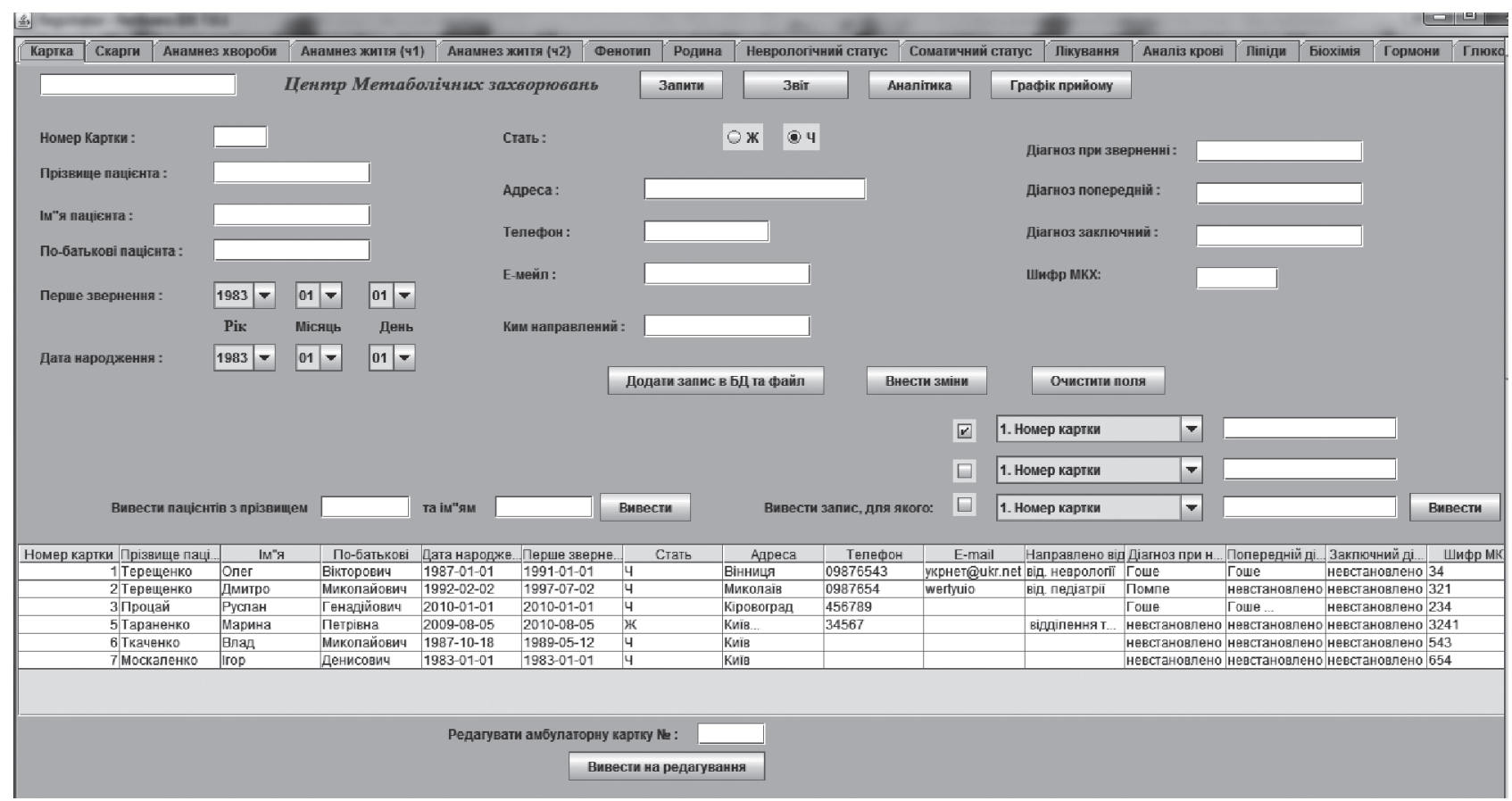

Рис. 1. Головна сторінка першої версії інформаційно-аналітичної системи ранньої діагностики орфанних захворювань

Об'єкт дослідження - інформаційно-аналітична система ранньої діагностики метаболічних захворювань, що представляє собою високопродуктивні паралельні розподілені та відмовостійкі програмні комплекси для обробки даних значних обсягів, зокрема характеристик організму.

Предмет дослідження - методи автоматизованого проектування та побудови програмних комплексів медичного спрямування, зокрема використання електронних протоколів ранньої діагностики, сформованих відповідно до сучасних медичних норм.

Матеріали та методи дослідження. Для створення помічника-консультанта для лікаря Центру орфанних захворювань НДСЛ ОХМАТДИТ» створено пілотну версію програмного забезпечення. Першим етапом став збір дослідних даних для побудови моделі розпізнавання, другим структурування даних і створення бази даних, третім - безпосередньо створення програмного забезпечення.

Дуже важливо було обрати групу пацієнтів із інформативно значущими клінічними та біохімічними показниками. Також у роботі застосовуються оціночні шкали, що змогли б допомогти оцінити цифрове значення вірогідності наявності у пацієнта того чи іншого спадкового орфанного захворювання.
Проблема діагностування саме орфанних спадкових захворювань полягає в тому, що є дуже велика кількість усіх характеристик організму пацієнта понад 10 000, і це число продовжує зростати, адже лікарі знаходять все нові й нові показники, що можна виміряти чисельно та що можуть свідчити про стан організму.

Результати та їх обговорення. В результатом роботи стало створення пілотної версії програмиконсультанта (рис. 1), що може бути встановлена на персональному комп’ютері лікаря для проведення початкового тестування.

Одна з основних цілей, що стоїть перед лікарем центру метаболічних захворювань у процесі його роботи, - вчасне та точне встановлення діагнозу для забезпечення подальшого правильного лікування.

Розроблена система призначена для проведення розпізнавання невідомої хвороби та визначення попереднього діагнозу, що допоможе лікарю прийняти правильне рішення.

У 2017 році науковці з Університету Аделаїди розробили систему, за допомогою якої можна автоматизувати процес пошуку захворювання у пацієнтів. Для цього використали 15 тис. знімків грудної клітки людей, старших за 60 років. Після обробки нейромережею даних за допомогою біомаркерів, остання змогла передбачити летальний результат 
для 69 \% випадків. Науковці стверджують, що такий результат притаманний і звичайним лікарям. Дослідники вважають, що розробка відкриває нові можливості для застосування штучного інтелекту в аналізі томограм, що може привести до більш раннього виявлення захворювань людини. Враховуючи цей факт, можна припустити, що схожа розробка для автоматизації процесу пошуку орфанного захворювання теж має всі шанси продемонструвати достойний результат.

Сьогодні у сфері спадкових орфанних захворювань не тільки в Україні, але й у світі відсутнє сертифіковане програмне забезпечення (ПЗ), що виконувало б консультуючу та інформаційно-аналітичну функцію. Дана робота є спробою створення та впровадження такого ПЗ на допомогу лікарям, які займаються лікуванням пацієнтів з орфанними захворюваннями, та пацієнтам для швидшого встановлення вірного діагнозу, а, отже, зростанню шансів на уникнення каліцтва, пов'язаного $з$ хворобою.

Важливо розуміти, що саме рання діагностика визначена пріоритетним напрямом української медицини. На жаль, встановлення хоч і правильного діагнозу, але з запізненням може призвести до досить сумних наслідків для здоров'я та якості життя пацієнтів.

Слід також зазначити, що у різних регіонах України є значна кількість пацієнтів із підозрою на спадкові орфанні захворювання, але не всі пацієнти мають змогу приїхати на лікування до НДСЛ
«Охматдит». Тому важливо акцентувати увагу на поширення даної інформаційно-аналітичної системи в регіональних орфанних центрах.

В основі роботи програмного комплексу лежить використання штучної нейромережі (рис. 2). Етапи реалізації мають таку черговість:

- збір даних для навчання;

- підготовка та нормалізація даних;

- вибір топології мережі;

- експериментальний підбір пропускної здатності мережі;

- експериментальний підбір параметрів навчання;

- власне навчання;

- перевірка адекватності навчання;

- коригування параметрів, остаточне навчання;

- вербалізація мережі з метою подальшого використання.

Збір даних для навчання мережі та їх обробка $є$ найскладнішим етапом вирішення завдання $[1,5]$. Набір даних для навчання повинен задовольняти декільком критеріям:

- репрезентативність - дані повинні ілюструвати справжній стан речей у предметній області;

- несуперечливість - суперечливі дані в навчальній вибірці призведуть до поганої якості навчання мережі.

Вихідні дані перетворюються до вигляду, в якому їх можна подати на входи мережі. Кожен запис у файлі даних називається навчальною парою або

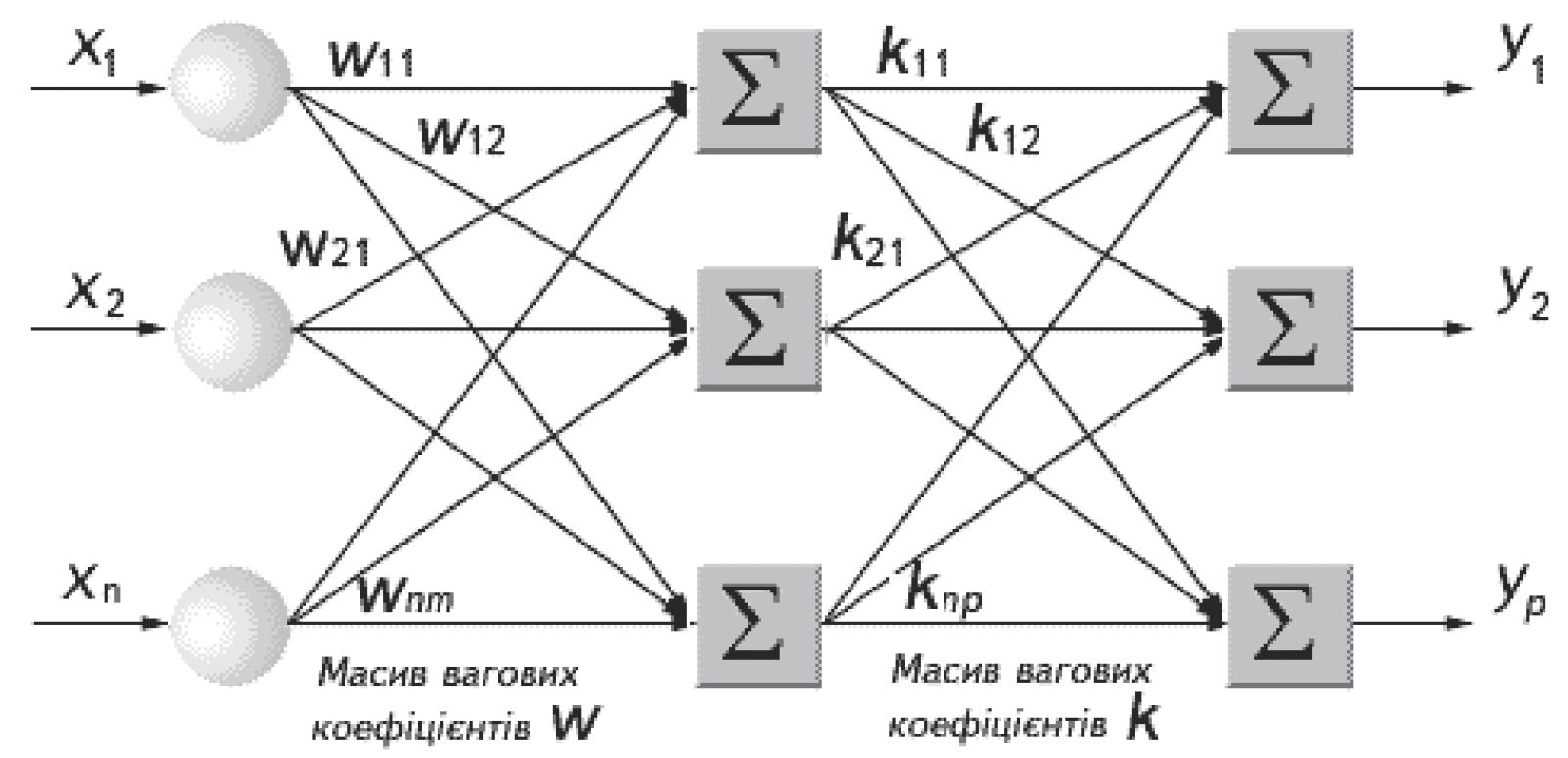

Рис. 2. Узагальнений схематичний вигляд нейромережі 
навчальним вектором. Навчальний вектор містить по одному значенню на кожен вхід мережі i, залежно від типу навчання (зі вчителем або без нього), по одному значенню для кожного виходу мережі. Навчання мережі на «неопрацьованому» наборі, зазвичай, не дає якісних результатів. Існує ряд способів поліпшити «сприйняття» мережі.

Залежно від обраного типу архітектури нейронної мережі, методу навчання, методів оптимізації система буде демонструвати різні результати в прогнозуванні.

Першу версію комплексу було спроектовано та розроблено у програмному середовищі NetBeans на мові програмування Java. В подальшому сплановано залучення можливостей використання Cloud Computing та створення повноцінного Web-порталу.

Висновки. Дослідження присвячено методам автоматизації процесу діагностування спадкових метаболічних захворювань з використанням інформаційно-аналітичної системи ранньої діагностики. Тематика є доволі актуальною, оскільки сьогодні відчувається недостатня забезпеченість центрів України саме програмним забезпеченням, що допомагало б проводити ранню діагностику.

Безперечно, як для економіки, та і для суспільства, інформаційно-аналітична система, що мала би змогу аналізувати великий об’єм медичних даних, встановлювати причинно-наслідковий зв'язок між станом організму та можливим розвитком хвороби i, як результат, - збереження здоров’ я та життя пацієнтів, має надзвичайне значення.

Запропоновані підходи до проектування відповідного програмного забезпечення є інноваційними у даній галузі та потенційно можуть призвести до отримання важливих наукових і практичних результатів.

Перші результати полягатимуть в полегшенні роботи лікарів, зменшенні обсягів паперової роботи. Довготривалі результати будуть полягати в якісному покращенні лікування, зумовленому раннім діагностуванням, i, як наслідок, - у збереженні здоров’я та життя пацієнтів.

\section{Література.}

1. Васильев В. И. Распознающие системы : справочник / В. И. Васильев. — Киев : Наукова думка, 1969. — 292 c.

2. Інструкція щодо заповнення форми первинної облікової документації № 025/о «Медична карта амбулаторного хворого № охорони здоров’я України 14.02.2012 № 110 / база даних «Законодавство України» ; офіційний вебпортал Верховної Ради України. - Режим доступу : http://zakon2.rada.gov.ua/laws/show/z0669-12.

3. Проект Концепції створення якісної системи надання допомоги хворим на рідкісні захворювання в Україні [Електронний ресурс] / Міністерство охорони здоров’я України // Щотижневик «Аптека». - Pежим доступу : http://www.apteka.ua/article/148265.

4. Хэгглин Р. А. Дифференциальная диагностика внутренних болезней / Р. А. Хэгглин ; пер. с нем. - М.: Триада X, 1997. - 794 с.

5. About MySQL [Electronic resource] / MySQL. - Mode of access : http://www.mysql.com/about/.

6. Collins F. S. A new initiative on precision medicine / F. S. Collins, H. Varmus // New Engl. J. Med. 2015. - Vol. 372, No. 9. - P. 793-795.

\section{References.}

1. Vasil'ev, V. I. (1969). Raspoznayushchie sistemy [Recognizing systems]: handbook. Kyiv: Naukova dumka [in Russian].

2. Ministry of Health of Ukraine (2012, February 14). Order No. 110: Instruction on filling out the form of the primary accounting documentation No. 025/0 «Medical card of the outpatient patient № ___. The Verkhovna Rada of Ukraine web site. Legislation of Ukraine. Retrieved from: http://zakon2.rada.gov.ua/laws/show/ z0669-12 [in Ukrainian].

3. Ministry of Health of Ukraine (2012, June 18) Draft Concept for the creation of a quality system for rendering assistance to patients with rare diseases in Ukraine. Retrieved from: http://www.moz.gov.ua/ua/print/ Pro_20120316_0.html [in Ukrainian].

4. Hegglin R. A. (1997). Differential diagnosis of internal disease. Moscow, Triada-X [in Russian].

5. About MySQL (n. d.) MySQL. Retrieved from : http:// www.mysql.com/about/

6. Collins, F. S. \& Varmus, H. (2015). A new initiative on precision medicine. New Engl. J. Med. 372(9), 793-795. 